\title{
EL CONCEPTO DE INCLUSIÓN SOCIAL
}

\section{THE CONCEPT OF SOCIAL INCLUSION}

\author{
JORGE CHUAQUI* \\ Universidad de Valparaíso \\ jorge.chuaqui@gmail.com \\ Colaboradores \\ DAVID MALLY** \\ RUBY PARRAGUEZ***
}

\section{Resumen}

Los conceptos de inclusión y exclusión están siendo cada vez más utilizados por el fin del Estado de Bienestar y las políticas actuales. Presentamos los diversos aspectos del problema, caracterizaciones del concepto, origen histórico, posibles marcos explicativos y hacemos una propuesta que generalizando los rasgos del concepto lo define como precariedad en cuanto a poder para la realización personal por la posición estructural de acuerdo a distintas dimensiones sociales, dándole un significado preciso y válido éticamente.

* Doctor en Ciencias Humanas, Profesor Titular del Instituto de Sociología de la Universidad de Valparaíso. Artículo recibido el 3 de noviembre de 2016 y aceptado el 26 de diciembre de 2016.

** Sociólogo, Universidad de Valparaíso.

*** Socióloga, Universidad de Valparaíso.

Revista de Ciencias Sociales - Número 69 (2016) - Universidad de Valparáíso - ISSN 0716-7725-Valparaíso, Chile 
Jorge Chuaqui, David Mally y Ruby Parraguez

\title{
Palabras clave
}

Poder social, inclusión social, exclusión social, integración social.

\begin{abstract}
Social Inclusion and Social Exclusion are widely employed in the present times because of the end of Welfare State and reductive policies. We try to present the diferent aspects and dimensions of the concept, historical, explicatory frameworks, and we make a general proposal characterizing then as lack or precarious position of power to personal fulfillment, respecting the multiple dimensions implied, giving to it an accurate and ethic content.
\end{abstract}

\section{Keywords}

Social power, social inclusion, social exclusion, social integration.

\section{Conceptos introductorios: poder social e intereses}

La definición [de poder social] que se dará aquí: 1) no señala el poder como atributos de sujetos o grupos considerados aisladamente de su contexto; 2) es más específica y restringida a un tipo especial de problemas que la que se da usualmente. El poder es una particular forma de relacionarse de los individuos o conjuntos de individuos con sus contextos de interacción y por tanto: a. depende de los individuos o conjunto de individuos; b. de las características de los contextos de interacción; c. del medio al cual se enfrenta dicho contexto de interacción; d. de la posición de los individuos o conjuntos de individuos en ese contexto de interacción frente al ambiente.

Definiremos el poder social como la capacidad de los individuos o conjuntos de individuos para hacer prevalecer el logro de sus intereses objetivos en el contexto de interacción. El poder social implica que la conducta de los individuos o conjunto de individuos puede llevar a que el contexto de interacción adquiera características tales que contribuya a que esos individuos o conjuntos de ellos logren en mayor medida sus intereses objetivos. Como parece claro, el poder puede derivar en parte no sólo de la posición de los individuos o conjunto de individuos en el contexto de interacción considerados, sino también de su posición en

Facultad de Derecho y Ciencias Sociales - Universidad de Valparaíso - Chile 
otros contextos de interacción que se interconectan con el primero a través del individuo en referencia o de otras formas. Cuando ello es así se lo denomina poder social externo. Cuando no es así, poder interno. En todo caso, al hablar de poder social hay que hacer explícito cuál es el contexto de interacción que se toma como referencia.

El concepto de poder social está ligado al de intereses, objetivos y manifiestos. Hemos definido estos conceptos como:

Intereses objetivos. El concepto se refiere al conjunto de objetos, (materiales y sociales, reales y simbólicos) a los cuales tendría acceso un sujeto por ocupar una posición, si a partir de dicha posición ejecutara la secuencia de actos más adecuada para lograrlos, siempre que a través de la apropiación de esos objetos obtuviera el mayor nivel, accesible desde su posición, de gratificaciones.

Puntualizando esta definición, los intereses objetivos están constituidos por un conjunto de objetos los cuales:

1. Son accesibles al sujeto desde su posición, siempre que

2. Este ejecute secuencias de actos determinados y,

3. Estos objetos deben ser los que brinden el mayor nivel de gratificaciones al sujeto, dentro de las posibilidades que le permite su posición en el contexto de interacción.

Los intereses manifiestos son los intereses tal como son conceptualizados o percibidos por los sujetos. En este caso son los objetos:

1. Que los sujetos los ven como accesibles desde su posición, siempre que

2. Estos ejecuten secuencias de actos determinados y,

3. Estos objetos deben ser los que los sujetos piensen que les brindan el mayor nivel de gratificaciones, dentro de las posibilidades que ellos visualizan les permite su posición en el contexto de interacción.

Aquí hay que puntualizar algunos aspectos. La caracterización de los intereses objetivos supone una reconstrucción teórica de cuales 
serían esos intereses, que pueden ser distintos de los intereses manifiestos. Los incumbentes de esos intereses deberían "descubrirlos" ampliando su conciencia respecto a la situación en que se encuentran y analizando las posibles vías de acción, que en todo caso significan un papel activo y creativo de los involucrados. Según pensamos, no se trata de determinar desde fuera e imponerles a los involucrados sus intereses objetivos en caso de discordancia con los manifiestos, sino acompañarlos para que ellos descubran sus intereses y se transformen en manifiestos. Al trabajar con sujetos o colectivos debe apoyarse los intereses manifiestos legítimos, sobre todo de los sujetos vulnerables, y despertar conciencia pero no pasar a imponerles un curso de acción desde fuera. Las personas tienen derecho a un papel activo y creativo, y en este sentido, no son un objeto de las políticas y de la acción de apoyo, sino sujetos con autodeterminación.

Respecto a los intereses de una pluralidad de personas, estos pueden ser intereses comunes, cuando los intereses que derivan de las posiciones de los sujetos son similares entre sí. Se habla de intereses colectivos cuando los intereses comunes sólo pueden lograrlos las personas organizándose en una colectividad, no individualmente.

La capacidad de realizar en mayor medida los intereses, y por tanto del poder, dependen de los sistemas de interacción en que se participe, de las posiciones que se ocupe en ellos y de características y conductas personales. Cuando se habla de poder, hay que hacer referencia al sistema de interacción donde se ejerce el poder. Así el poder del jefe de familia en la familia, es distinto al poder que puede tener la misma persona en la empresa en que trabaja, pero están conectados, ya que el ingreso que recibe por trabajar en la empresa aumenta su poder en la familia, y respecto a la familia es poder externo.

\section{Mirada histórica del concepto de exclusión social}

Un antecedente previo a la denominación del concepto de exclusión es ubicada en las figuras clásicas de la sociología. No es que el término exclusión social surgiera junto con Durkheim o Marx, sino que estos autores ya habían señalado expresiones que diagnosticaban los problemas de las sociedades de ese entonces. Por ejemplo el concepto

Facultad de Derecho y Ciencias Sociales - Universidad de Valparaíso - Chile 
de desviado o alienado, si bien poseen posicionamientos epistémicos diferentes y explican ciertos fenómenos sociales, contienen incidencia en ese modelo explicativo que recubre la lógica de la exclusión social; "dentro/fuera".

Según Rizo ${ }^{2}$, el contexto histórico desde donde surge el concepto de ES es el que acaeció en la Europa posguerra. Dentro de los factores que hacen posible la construcción de este concepto, uno de los men-

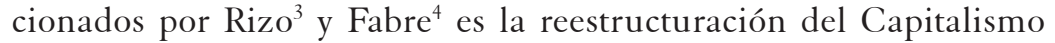
posterior a la Segunda Guerra Mundial. Tales implicancias no sólo se ponen en juego en relación a lo económico, sino que existe una transformación del aparato público y un replanteamiento del Estado, ahora como un Estado Benefactor o Social. Por ende, el concepto de ES debe su origen en cierta medida a los cambios implantados en el modelo de desarrollo capitalista de la segunda mitad del siglo XX.

Durante 1957 el Cura Joseph Wresinski instaló el concepto de Exclusión en relación al Movimiento de Ayuda a toda desgracia, enfocada a lo que conocía como Cuarto Mundo. Tal concepto tenía la función de explicar la situación de los más pobres. No obstante, es Rene Lenoir en 1974, el que contribuye a asociar el concepto como un desplazamiento, que gravita en la postergación y apartamiento de los beneficios sociales y del mercado del trabajo 5 . Si bien esto era una contribución de origen francés, en Inglaterra la discusión se hacía a través del concepto de infraclase (underclass), lo cual era un criterio de estratificación social que sería útil en ese entonces para mencionar un

1. JIMÉNEZ, M.: "Aproximación teórica de la exclusión social: Complejidad e imprecisión del término. Consecuencias para el ámbito educativo”. En: Revista Estudios Pedagógicos. N 1, pp. 173-186. 2008

2. RIZO, A.: “¿A qué llamamos exclusión social?”. En: Revista de la Universidad Bolivariana. $\mathrm{N}^{\circ} 015$, pp. 1-14. 2006.

3. Íbid.

4. FABRE, M.: Consideraciones en torno al concepto de exclusión social. Acciones e investigaciones sociales. Universidad de Zaragoza. 2002.

5. RIZO, ob. cit.

Revista de Ciencias Sociales - Número 69 (2016) - Universidad de Valparáíso - ISSN 0716-7725-Valparáiso, Chile 
fenómeno similar al que ocurría en Francia, el cual señalaba en síntesis que el excluido era resultado de factores estructurales y que su condición se debe a la inadaptación de él mismo hacia la sociedad.

Para el caso de América Latina, teniendo en cuenta el sesgo de la generalización prematura, es posible desde un plano histórico observar cómo las transformaciones de los modelos de desarrollo societal, con un énfasis en el patrón de acumulación, dan señales de una fuerte crisis de los mecanismos de integración que a nivel global se han venido estructurando desde los años $50^{\prime 6}$. Consecuencias de dicha crisis se ubicaría la exclusión social y un bagaje de conceptos que se utilizan desde planos ético-políticos diferentes, para tratar de dar cuenta de los principales problemas que surgen en los modelos de desarrollo de las sociedades occidentales, fundamentalmente.

A partir de los años 50' en Latinoamérica, se trató de hacer un giro a las primeras décadas del siglo XX, tratando de instaurar un Estado desarrollista y un modelo de acumulación basado en el mercado interno o por sustitución de importaciones. A consecuencia de este giro, el aparato estatal y la fuerza del trabajo se vuelven puntos claves para lograr generar este viraje, que otorgaba ciertos derechos sociales básicos, tendientes a mejorar la calidad de vida de las poblaciones latinoamericanas, todo bajo la premisa de la modernización de las sociedades.

Las décadas de 1970 y 1980 exhiben la imposición de un modelo de acumulación centrado en el mercado, el cual amputa las políticas sociales universalistas del Estado Desarrollista y pone en juego políticas sociales focalizadas en ciertos grupos de la población, para contrarrestar las consecuencias perversas y no las verdaderas causas de la exclusión.

Si bien la comprensión estructural posible de lograr en la década de los 60-70' ponía el acento en explicar la ES a nivel de conflicto de clases, es durante los años 80 ' desde donde se comienza a dar un nuevo enfoque al concepto de ES, ya que principalmente en esta década se observan reestructuraciones a nivel Estatal, de la mano con una profundización de las estrategias Neoliberales en cuanto a reformas

6. SARMIENTOS, J.: "Exclusión social y ciudadanía política. Perspectivas de las nuevas democracias latinoamericanas”. En: Revista Última Década. $\mathrm{N}^{\circ} 8$, pp. 53-69. 1998

Facultad de Derecho y Ciencias Sociales - Universidad de Valparaíso - Chile 
financieras y económicas, que exhiben aún más la falacia de la catalaxia del mercado como régimen de organización social. El fin de un Estado garante de derechos sociales básicos se diluye mientras el mercado expande sus dominios y obliga al aparato público a estrechar su margen de acción e intervención en la sociedad. Según Sarmientos "la integración social fue sacrificada a favor de la integración sistémica; es decir, se priorizaron los requerimientos funcionales de la acumulación capitalista en detrimento de la cohesión social". Según este mismo autor, "los fenómenos de exclusión social tiene en la contradicción de la intervención social del Estado una de sus fuentes. La otra tiene su origen en el mundo del trabajo"

Las interpretaciones realizadas en torno al conjunto de personas que no se adaptaban al desarrollo del Capitalismo generó una amplia discusión y por ende una fuerte crítica con propuestas analíticas implicadas al por qué de este verdadero problema social. A los pies de esta tensión y en un contexto social, cultural y político de alto dinamismo las respuestas a tales problemas se encaminaban por distintos senderos y las confusiones terminológicas generaban entrampamientos discursivos y juegos del lenguaje que hasta el día de hoy tienen una cierta vigencia.

\section{El concepto de exclusión social}

Existe la tentación, expresada en diversos análisis, de caracterizar el concepto de exclusión por el simil dentro-fuera de la sociedad, pero en rigor las personas nunca están "fuera" de los sistemas sociales. La exclusión, de manera preliminar, será entendida como una relación social que impide u obstaculiza el logro de una mejor posición social, superar una situación o un derecho a que se debiera tener acceso. Esto es sólo una primera aproximación ya que el concepto será definido de manera precisa más adelante. Esta relación puede afectar a categorías sociales (conjuntos de posiciones con características comunes sin que haya necesariamente interacción directa entre las posiciones con dichas características) o sistemas de interacción o grupos sociales (conjuntos

7. SARMIENTOS, ob. cit., p. 58.

Revista de Ciencias Sociales - Número 69 (2016) - Universidad de Valparaíso - ISSN 0716-7725-Valparaíso, Chile 
de personas en interacción). Como veremos, la exclusión puede darse en diversas relaciones, niveles o rasgos de la estructura social, que especifican sus manifestaciones concretas, y que pueden ser de tipos muy variados.

De manera introductoria podemos caracterizar a la exclusión como un proceso dinámico multicausal, relativo y estructural ${ }^{8}$. Dinámico frente a la complejidad de la realidad social, la multietiología de los fenómenos sociales debido a la interconectividad de los sistemas y sus elementos constituyentes. Esto impide que siga un proceso lineal fijo, ya que en él pueden incidir con diferente intensidad los distintos factores de riesgo de la exclusión, así como no representa un estadio acabado, si no que sus características, en una situación específica, tiempo y contexto particular (carácter relativo), regeneran y alimentan el proceso.

A su vez la exclusión tiene carácter estructural ya que sus causas generales se asientan en la estructura económico política de una sociedad y la cultura que se genera entre estas dimensiones. No es un proceso que sea parte de un orden natural de la sociedad en su desarrollo social. Más bien forma parte de cierto tipo de desarrollo.

Más adelante veremos como esta situación desfavorable impide la realización personal de los sujetos y plantearemos la relevancia ética del concepto como antítesis a la exclusión.

Aún como introducción y de manera no sistemática, podemos reconocer algunas manifestaciones de la exclusión en una sociedad como la nuestra.

Son reconocibles tres niveles en los cuales se manifiesta la exclusión:

1. La exclusión puede manifestarse en el impedimento o la dificultad para ingresar a algún sistema social, por ejemplo un tipo de sistema educativo, tipo de trabajo, u otro grupo de socialización mediado por razones económicas, factores religiosos, ideológicos, de género o de otras clases.

8. JIMÉNEZ, ob. cit.

Facultad de Derecho y Ciencias Sociales - Universidad de Valparaíso - Chile 
2. También es posible reconocer la exclusión en la dificultad para acceder a servicios o derechos fundamentales, como la salud, la educación, cultura, etc.

3. Por último se puede reconocer la exclusión para mantenerse dentro de un mismo sistema, grupo o servicio por malas condiciones a nivel relacional, al estar deterioradas las relaciones sociales, verse dificultado el contacto social y la posibilidad de entablar relaciones de buena calidad. Esto debido a mecanismos de diferenciación social que operan junto a la discriminación y el estigma.

A su vez podemos reconocer algunos factores o causas inmediatas por las cuales las personas pueden verse excluidas:

1. Por precaria clase social:

a. Para acceder a derechos sociales de calidad como la educación, salud, vivienda y trabajo.

b. Para ingresar o mantenerse en un sistema con relaciones sociales de calidad por condiciones socioeconómicas: vestuario, condiciones de vivienda, posibilidad de transporte, tendencias culturales de expresión verbal o paraverbal.

2. Por localización socio-territorial aislada, marginal u otra.

a. Dificultades para acceder a derechos sociales de calidad como la educación, salud, vivienda, trabajo.

b. Para habitar en un ambiente amigable.

c. Para construir redes y lazos sociales.

3. Por estar catalogado bajo alguna categoría médica o jurídica que denote anomalía social (ya sea enfermedades crónicas, discapacidades, enfermedades contagiosas, categorías de conflictividad moral (homosexualidades, por ejemplo), antecedentes penales, otros.

4. Por categoría de género, como ser mujer.

5. Por categoría de edad, como ser anciano.

6. Por apariencia física fuera del margen de "normalidad", como una anomalía física, estilo diferente de vestir y peinar, 
tener apariencia asociada a algún estereotipo social negativo

("flaite", vagabundo, delincuente, prostituta, entre otros).

7. Por discapacidad perceptible (psíquica, intelectual o física).

8. Por preferencias sexuales.

9. Por militancia política.

10. Por profesar religión.

11. Otras razones ideológicas.

12. Por pertenecer o ser originario de una etnia.

Recordemos el concepto de posición social que habíamos caracterizado de la siguiente manera: "Si consideramos todas las determinaciones o consecuencias para cada individuo por participar en un sistema de interacción, no sólo respecto a otros individuos específicamente, como en el status, sino además respecto a su relación con el sistema en su conjunto, a las relaciones del sistema con el ambiente, etc., incluyendo las determinaciones surgidas del concepto de intereses objetivos y poder social $[. . . \ldots \ldots \ldots . .$.$] tenemos el concepto de posición$ en el sistema, y si consideramos todas sus posiciones en los sistemas en que participa, posición social global. Debe destacarse que el peso o relevancia de las distintas posiciones del individuo no es el mismo para determinar su posición social global. Tal como al concepto rol corresponde al de status, al de posición social corresponde el de práctica social, que son las actividades realizadas por quien detenta una posición, ligadas de una u otra manera al logro, mantención o modificación de los intereses derivados de dicha posición”.

\section{Definición de exclusión}

De acuerdo a la posición o estatus dentro de los sistemas o subsistemas sociales se dan diversos grados de poder en el sentido de capacidad de lograr sus intereses, pueden existir barreras o limitaciones en la posición o estatus, que se expresan en distintas dimensiones, como en cuanto a servicios de salud, educación, acceso territorial a servicios, dificultad para acceder a una posición laboral o clase social de calidad, etc. Ahora podemos definir de manera rigurosa el concepto de exclusión social como sigue. La exclusión social está constituida por limitaciones

Facultad de Derecho y Ciencias Sociales - Universidad de Valparaíso - Chile 
o degradaciones del status de una categoría social o sistema de interacción que se expresan multidimensionalmente en cuanto a precariedad de poder o bien barreras estructurales de las posiciones sociales de una categoría social o sistema de interacción que se expresan en limitaciones multidimensionales a su poder.

En la enumeración de categorías de exclusión en que se aplica esta definición, hemos visto que puede ser (A) por la posición en clase social desmedrada (categoría 1 de las mencionadas en la enumeración anterior), o posición respecto a inserción laboral o forma de tener sustento en general, (B) por limitaciones o degradaciones del estatus (de género, de discapacitado, de enfermo, de pertenecer a una religión, ideología o tendencia política o de otro tipo, etc.) (categorías 3, 4, 5, 6, $7,8,9,10,11)$. (C) También por barreras en la dimensión territorial o cultural (categorías 2 y 12). Desde este punto de vista nuestra definición en el recuadro cubre todas las variantes de las diversas formas o fuentes de la exclusión, evitando caer en una casuística de sus formas.

Los conceptos de clase social y de exclusión tienen distinto origen teórico: el de clase social ligado al análisis de la lucha de clases, y de la lucha política en general, siendo usado también para examinar preferencias y estilos de vida, en cuanto a las relaciones de poder o dominación entre las clases; el de exclusión se vincula al concepto de ciudadanía y los derechos ciudadanos que debería garantizar un Estado de Bienestar. Está orientado a diseñar políticas de inclusión desde el Estado para superar la exclusión. En el caso de las clases, en cambio, se trata de actuar políticamente para modificar la relación entre las clases. Pero ambos, como hemos visto, tienen como nudo central el poder asociado a las posiciones sociales.

El trabajo y la propiedad, que definen las clases sociales, juegan también un papel central en la exclusión que tiene características multidimensionales. El trabajo y la propiedad cumplen un papel de primera importancia en la sociedad y en la vida de individuos y grupos. El trabajo y la propiedad brindan los medios para el sustento autónomo de los individuos adultos y es el elemento crucial en la calidad de vida. El trabajo y la propiedad de calidad brindan reconocimiento social y es uno de los componentes fundamentales del prestigio social. La posición de clase del individuo y su familia, es decir su ubicación en la estructura 
social, los bienes a que tiene acceso, los servicios ideacionales y no ideacionales que recibe, el hábitat o espacio en que mora, sus posibilidades de acceder a servicios recreacionales, dependen del trabajo en alguna parte de la estructura de los miembros adultos de la familia y/o propiedad que se posea. Los miembros de las familias que tienen un trabajo remunerado o propiedad, por ese hecho tienen más poder dentro de ellas y tienen más autonomía para tomar sus decisiones, están más empoderados y son menos dependientes.

\section{Factores Explicativos de la ES}

Los factores que explicarían el por qué de la ES son distintos. No es posible asociar directamente ciertos factores si estamos asociando en un nivel analítico diferentes dimensiones donde ocurren los procesos de ES. Por ende, la exploración de los factores es un acercamiento a la multicausalidad que recubre dicho fenómeno.

- Partiremos exponiendo la corriente marxista tradicional como una perspectiva que ve la exclusión económica como producto del desarrollo desigual de la sociedad capitalista que concentra el poder económico en pocas manos y que se desarrolla de manera no armónica, habiendo en pos de la productividad guiada sólo por la obtención de ganancia como subproducto entre otros, de una población flotante o ejército industrial de reserva, cesantes temporales por los ajustes de la producción, otros sectores que con el tiempo se desvinculan de la producción o lumpenproletariado (vagabundos, delincuentes, prostitutas, etc.) y otras categorías. El marxismo enfatiza el protagonismo de los partidos políticos proletarios para superar los problemas y transformar la sociedad en una más justa (con menos exclusión, J.CH.), y el papel de las organizaciones derivadas de base. Sin embargo, debe cuidarse que dichas organizaciones representen genuinamente a quienes dicen representar y no sean controlados oligárquicamente. En los socialismos "reales" de Europa del Este, los sindicatos y otras organizaciones derivadas eran controlados en gran medida desde arriba por el Estado.

Facultad de Derecho y Ciencias Sociales - Universidad de Valparaíso - Chile 
- Recogiendo el trabajo analítico y sintético de otros autores que identifican algunas perspectivas de explicación de la exclusión, encontramos a Barros et al ${ }^{9}$, según los cuales hay miradas que se organizan en torno a la identificación de factores que explicarían la exclusión social.

1. La primera perspectiva es rotulada como el de la "solidaridad". De origen francés, dicha perspectiva señala que la exclusión se debe entender como una anomalía, o defecto de la sociedad en su conjunto. Por ende, es de retener que la exclusión social es considerado como un "estar fuera" del "consenso valórico" ${ }^{10}$. Dicho enfoque incuba la perspectiva de la integración social, pues la exclusión social queda remitida a una forma patológica, ya que en dichos grupos existiría una resistencia al imperativo moral que ha fijado la sociedad, en esta suerte de contrato social.

2. La segunda perspectiva pertenece a la ideología política liberal. Bajo este enfoque, la exclusión social es entendida como fruto de la interacción social. En ese sentido, la exclusión estaría determinada por las decisiones de los individuos, y no por determinaciones del sistema social. La exclusión es explicada en gran medida por el tipo de intercambio que las personas realizan.

3. La tercera perspectiva es denominada la del "monopolio", y es asociada al "Régimen de la social Democracia europea"11. En dicha perspectiva, la exclusión social es estructural al sistema, y está fuertemente determinada por la posición que tienen ciertos grupos respectos a otros en torno al poder. Por ende, unos determinarán la posición del otro dentro del sistema social.

9. BARROS, P., Ríos, D., Torche, F.,: Lecturas sobre la Exclusión Social. Organización Internacional del Trabajo (OIT). Santiago de Chile. 1996.

10. Íbid., p. 4.

11. Íbid., p. 5.

Revista de Ciencias Sociales - Número 69 (2016) - Universidad de Valparáíso - ISSN 0716-7725-Valparaíso, Chile 
- Según Rizo ${ }^{12}$, a nivel político-ideológico hay tres tipos de modelos explicativos:

- Modelo de la Solidaridad Republicana: Ruptura de los vínculos sociales y la responsabilidad del Estado en la cohesión social.

- Modelo Liberal de la Especialización: Explica la ES por distintos intereses y capacidades de los individuos dentro del mercado y la sociedad.

- Modelo Socialdemócrata del Monopolio: La ES viene de la competencia por los recursos y las reglas establecida por los grupos dominantes.

- Otros modelos como los propuestos por Laparra et al ${ }^{13}$ generan una distinción a partir de distintas explicaciones que se le ha dado a la ES. Algunas de las causas de la ES serían las referidas a:

- Los excluidos son personas que no quieren seguir normas y estilos.

- Es preciso incentivar y disciplinar.

- La ES es producto de una discriminación activa sobre ciertos grupos sociales estigmatizados.

- Es posible dentro de este marco que exista infraclases, y procesos de autoexclusión.

- El por qué estaría relacionado con el debilitamiento de la familia a partir de los Movimientos contraculturales de los años 60', además de la excesiva privación del Estado.

- Otra postura, mucho menos conductista, señala que las causas de la ES se vinculan con los procesos de desindustrialización y la revolución tecnológica. Buena parte de los trabajadores

12. RIZO, ob.cit.

13. LAPARRA et al, ob. cit.

Facultad de Derecho y Ciencias Sociales - Universidad de Valparaíso - Chile 
han quedado obsoletos ante las transformaciones del mundo del trabajo. El excluido se genera por las deficiencias de sus capacidades de funcionamiento para insertarse a la sociedad posindustrial.

- Por otra parte hay factores estructurales que operan en los procesos de ES, no obstante, no sólo actúan en la estructura productiva, sino que hay otros fenómenos, que de alguna manera se han mencionado anteriormente. Estos también son posibles variables que inciden en la ES:

a. Transformaciones en las formas de convivencia.

b. Transformaciones del Estado de Bienestar.

c. Transformaciones producidas en el mercado laboral.

En los modelos explicativos de la exclusión social priman las explicaciones en torno a la transformación del aparato Estatal y las referidas a la estructura productiva, con énfasis en las modificaciones del mercado del trabajo. No obstante, no se niega en absoluto las interpretaciones sobre las transformaciones de los modos de vida o las formas de convivencia. Las transformaciones que se han realizado sobre el modelo Capitalista han apuntado también sus dardos a la vida privada y en la vida cotidiana, con especial énfasis en los mecanismos de socialización social y cultural.

Para Sarmientos ${ }^{14}$, los posibles claves para explicar los fenómenos de exclusión social deben buscarse en el rol del Estado (2) y en el mercado del trabajo (3). En primer lugar, si se considera como factor explicativo las transformaciones del Estado de Bienestar (2) en la sociedad, las consecuencias se ven en la castración de las protecciones sociales garantizadas por este Estado Protector, deteriorando inmediatamente las condiciones sociales de vida. Dichas condiciones mínimas de igualdad (en el sentido de acceso a bienes sociales esenciales como, educación, trabajo, salud, vivienda, protección en la vejez, entre otros), se ven vulneradas, y con ello la exclusión social de grandes sectores de la sociedad que veían en la intervención del Estado un modo de estar integrado a la sociedad de la cual son parte.

\section{SARMIENTOS, ob. cit.}

Revista de Ciencias Sociales - Número 69 (2016) - Universidad de Valparáíso - ISSN 0716-7725-Valparáiso, Chile 
A nivel de transformaciones producidas en el mercado laboral, es posible mencionar que con la emergencia de un modelo de producción denominada posfordista, y con la introducción de nuevas tecnologías en un contexto de modificaciones de las relaciones laborales, ya el trabajo ha dejado de ser el gran integrador, como lo había sido en los inicios del siglo XX. En este sentido, la exclusión social no estaría atribuida a la falta de calificación de la fuerza de trabajo, sino a la forma excluyente con que operan las relaciones de producción y el empleo ${ }^{15}$.

Ulrich Beck ${ }^{16}$, señala que lo que está realmente en juego es la concepción misma de trabajo, como elemento cohesionador de la vida, como mecanismo de integración y como gran articulador de las relaciones sociales. Jiménez ${ }^{17}$, a partir de lo anterior señala que "la vida personal y social, sus tiempos y sus ámbitos, está en gran medida condicionada por el trabajo, y es a través de él cómo la inmensa mayoría de las personas obtiene los recursos que necesita para sobrevivir y que le permiten acceder a productos y servicios que lo definen socialmente como "integrado".

Empero la centralidad del trabajo dentro de los procesos multicausales de la exclusión social, van más allá de las cuestiones del desempleo y el acceso al mercado del trabajo. También no menos importante es de analizar las manifestaciones a través de las privaciones y barreras que impiden una participación plena en la educación, en la salud, en el medio ambiente, en la vivienda, en la cultura. Es por eso que en la actualidad el espectro de la exclusión social cubre también dentro de sus categorías a la exclusión étnica, ciudadana, de género, de privados de libertad, entre otras posibles.

Desde estos puntos de vista, explicar cuáles son las causas y posibles soluciones a la exclusión depende del enfoque teórico que se tenga de la sociedad, que va desde el marxismo y el funcionalismo al postmodernismo, pasando por las numerosas perspectivas teóricas,

\footnotetext{
15. Íbid.

16. BECK, Ulrich: La sociedad del riesgo. Paidós, 1998.

17. JIMÉNEZ, M., ob. cit., p. 182
}

Facultad de Derecho y Ciencias Sociales - Universidad de Valparaíso - Chile 
muchas veces en conflicto unas de otras. Nosotros simplemente hemos querido clarificar conceptual y éticamente la exclusión y las políticas de inclusión.

\section{Dos dimensiones importantes en la exclusión}

Además del trabajo y propiedad, en las manifestaciones de la exclusión están la dimensión territorial y cultural.

\section{El ámbito territorial}

La mayor parte de las personas adultas de la sociedad reparten su tiempo entre cumplir una tarea u obligación social y el disfrute de relaciones afectivas y de consumo. El centro en que se organiza el consumo es la familia. Algunos adultos cumplen su tarea u obligación social al interior de la familia, como las mujeres que sólo trabajan como dueñas de casa, desempeñándose en quehaceres domésticos y con el mayor peso en la crianza de los hijos. Pero, en la gran mayoría de los casos, para tener los recursos que permitan el consumo al interior de la familia, uno o más miembros adultos de ella deben desempeñar su obligación social en un trabajo remunerado fuera de ella, que les permite obtener los ingresos monetarios necesarios para el consumo. La actividad de trabajo fuera de la familia se da en empresas u organizaciones privadas o en organizaciones que pertenecen al Estado.

En las organizaciones en que se trabaja remuneradamente, la magnitud del ingreso es distinta para las diversas posiciones sociales que se ocupan dentro de ellas. La escala de ingresos, en la forma de ganancias, sueldos o salarios, se asocia al concepto de propiedad, al grado de autoridad de las posiciones y al grado de educación o capacitación que requiere su desempeño. En este sentido en una gran empresa puede darse toda la gama en la distribución de los ingresos, desde la apropiación de grandes ganancias por parte de los propietarios, altos sueldos entre gerentes y los profesionales más calificados, sueldos intermedios en ejecutivos de menor rango y capataces, hasta llegar a los salarios más bajos en ocupaciones manuales sin ninguna calificación.

¿Qué diferencia territorialmente a estas personas? No es frecuentemente el lugar en que trabajan, si todos ellos trabajan en las

Revista de Ciencias Sociales - Número 69 (2016) - Universidad de Valparáíso - ISSN 0716-7725-Valparaíso, Chile 
mismas empresas. Lo que diferencia territorialmente a estas personas es el lugar donde viven ellos y sus familias. Y esto tiene una explicación. Las familias habitan en viviendas que al ser ocupadas por ellas constituyen hogares. El consumo y parte del disfrute se realiza en familia, donde se busca apoyo emocional y psicológico y donde se puede organizar el ocio recreativo. Considerando los valores de nuestra sociedad, la familia y la recreación en familia constituyen parte importante de la realización personal. Pero la distribución geográfica de los hogares está asociada a los ingresos, y considerando que de acuerdo a la calidad de la urbanización y edificaciones, y los servicios disponibles, varía el precio de los terrenos y las edificaciones. Como las personas de una gran empresa trabajan juntas, pero se diferencian en sus ingresos, no viven juntas debido al acceso diferencial dado por los ingresos disponibles, a los espacios urbanos y las viviendas que hay en ellos.

Esto lo comprobamos empíricamente en un Diagnóstico del Desarrollo Social de la $V^{\text {a }}$ Región que realizamos para SERPLAC en 1977. El análisis mostró una alta correlación (coeficiente $r=0,75$ ) entre el desarrollo industrial de las provincias y el porcentaje de las más altas ocupaciones, pero esa correlación era nula a nivel comunal, lo que indica que no coincide la comuna en que se trabaja con aquella en que se vive, y por ser las comunas más homogéneas, se puede afirmar que están estratificadas.

Además, las personas de trabajos precarios o de trabajos estables de bajos ingresos, informales y de la contracultura, las más desprotegidas de todas en la sociedad pueden concentrase en verdaderos guetos en la periferia, en que la calidad de vida, la calidad de la urbanización y el acceso a parques y espacios públicos de disfrute, el acceso a buenos colegios para sus hijos y otros servicios urbanos pueden ser muy escasos. Si la política habitacional para los sectores postergados busca el menor costo posible, se tenderán a acentuar las diferencias sociales territorialmente, lo que afectará la calidad de vida y las posibilidades de realización personal de sus habitantes. Pero una misma magnitud de inversión en política habitacional podría arrojar resultados parcialmente diferentes si se considera en el diseño las características de los espacios y servicios que permiten una mayor realización personal y familiar elevando la calidad de vida.

Facultad de Derecho y Ciencias Sociales - Universidad de Valparaíso - Chile 
Siguiendo esta lógica, la segregación territorial por sus condiciones sociales de surgimiento (sociedad de desigualdad estructural, políticas sociales de maximización de recursos en la construcción y localización de viviendas), puede considerarse nuevamente un efecto de una exclusión mayor. Por otra parte estas condiciones de segregación y tendencias de ubicación territorial generan a su vez otras condiciones de exclusión, ya que como se ha dicho, dificultan el acceso a servicios y derechos básicos, por distancia y por calidad de los servicios (adecuados al lugar donde se realizan, mediado principalmente por condiciones económicas), dificultan la posibilidad de acceder a otras fuentes laborales, educacionales, de distracción y cultura y a otro tipo de relaciones sociales, dificultando el encuentro social, contacto y vínculo de calidad. En circunstancias la población en que se vive es fuente de estigmatización a la hora de buscar un mejor trabajo, reproduciendo la exclusión. Refuerza sumado a esto, aspectos culturales como la sobrevaloración del estatus social y su contracara, el simulacro y el culto a la apariencia, así como la discriminación y el estigma.

En resumen, la exclusión por trabajo o actividad para el sustento económico y la exclusión en cuanto al acceso a servicios del Estado tienen expresiones territoriales en el sentido que esos sectores se concentran usualmente en determinados espacios urbanos deteriorados, con deficiente urbanización y medios de comunicación a través del transporte y acceso a servicios esenciales. Pueden, en algunas situaciones, constituir verdaderos guetos y también sectores manejados por la droga y la delincuencia, que "marca" estigmatizando al resto de los pobladores.

Aunque no resuelven la totalidad de los problemas, las políticas de participación de la comunidad en los procesos de urbanización para introducir transformaciones en pro de un barrio más amigable, contribuyen a mitigar la exclusión territorial.

Las relaciones territoriales, como una de las dimensiones de los sistemas sociales en nuestras sociedades, conducen a que haya sectores que no pueden realizar adecuadamente sus intereses económicos, sociales y culturales y por tanto los dejan en posición desmedrada en dichas relaciones de poder.

Revista de Ciencias Sociales - Número 69 (2016) - Universidad de Valparáíso - ISSN 0716-7725-Valparáiso, Chile 


\section{El ámbito cultural: etnias, discriminación}

Dentro de un territorio en que predomina una ideología y cultura hegemónica, puede haber, por ejemplo otros grupos étnicos con cosmovisiones diferentes, que inicialmente ocupaban un territorio pero que parcialmente pueden haber migrado a otros territorios de la cultura hegemónica. Esta cultura y cosmovisión étnica distinta a la hegemónica choca y muchas veces no es considerada adecuadamente en las políticas estatales y puede provocar rupturas en la vida cotidiana, siendo por tanto un factor de exclusión, donde se aplican también todas las conceptualizaciones relativas al conflicto cultural. Es importante, para una adecuada política de inclusión de estos grupos, que sean reconocidos constitucional y legalmente, para que se considere y no se atropellen su cosmovisión y derechos en las políticas públicas y privadas que les atañen. Hay también subculturas menos enraizadas, de grupos particulares, como algunos grupos juveniles, que pueden dar origen a formas de discriminación y exclusiones parciales.

Por otro lado hay otras formas de exclusión que se dan al interior de grupos y subsistemas de la sociedad. ¿Qué significa la discriminación?

Los roles de las personas dependen de características adscritas o adquiridas, como género, edad, posición en la familia, etc. Asociado a un rol hay un status. El status puede consistir en determinados derechos, pero también en limitaciones y degradaciones. Estas limitaciones y degradaciones, cuando alcanzan un cierto nivel, o afectan algún aspecto importante de la interacción, constituyen una discriminación, que puede afectar una, alguna o muchas áreas de las situaciones de la persona en los grupos y sistemas. Estas discriminaciones constituyen formas de exclusión. El estigma constituye una forma más intensa de la discriminación.

Desde este punto de vista, constituyen formas de exclusión:

i. La discriminación hacia la mujer.

ii. La discriminación hacia la tercera edad (considerándolos como parcialmente incapacitados).

iii. La discriminación hacia los discapacitados (no considerando sus potencialidades) y como punto remarcable, la discri-

Facultad de Derecho y Ciencias Sociales - Universidad de Valparaíso - Chile 
minación hacia el discapacitado psíquico o enfermo mental (que además de la negación de sus capacidades, se lo considera como desviado) $)^{18}$.

iv. La discriminación hacia ciertos grupos juveniles, que por sus rasgos culturales o formas de vestir, se los considera como desviados.

18. Como ha mostrado el sociólogo Talcott Parsons el rol de enfermo es construido socialmente, no es simplemente algo dado por la naturaleza. El rol de enfermo mental es más específico y hay toda una construcción social al respecto, también desde el punto de vista de la psiquiatría, como han descrito Michael Foucault y Roger Bastide. Las enfermedades mentales, a diferencia de las solamente biológicas, tienen que ver con conductas, conductas que son evaluadas socialmente y que en estos casos son fuertemente estigmatizadas por el sentido común y la psiquiatría. Desde este punto de vista, el estigma es una de las barreras sociales, enraizadas en la construcción social del enfermo mental, con que deben bregar las personas rotuladas de esta manera. Muchas de estas características de la construcción social de enfermo mental se atribuyen, sin plena justificación, a características biológicas de los individuos. Así por ejemplo, los síntomas negativos de la esquizofrenia muchas veces se atribuyen a características del desarrollo endógeno de la enfermedad, habiendo razones para suponer que más bien son el resultado de un proceso en que la interacción del enfermo con el medio social es fundamental. Aparentemente también se supone que hay una pérdida de valores sociales en las personas con esquizofrenia, lo que contradice los resultados de una exhaustiva investigación empírica con 150 personas de todos los sectores sociales afectadas de esquizofrenia, que muestra que los valores religiosos y políticos, tanto en tipo como en intensidad, son los mismos que los del resto de la población. Todas estas suposiciones débilmente fundadas estarían justificando someterlos a un proceso forzado de adaptación social como paso previo a la integración, proceso que hasta ahora no ha resuelto para la gran mayoría sus problemas vitales fundamentales y a los que aspiran: tener un trabajo digno y una pareja estable con la que puedan formar su propia familia. Al contrario, el proceso de adaptación forzada conduce a la falta de iniciativa y a la pasividad, que obstaculizan el desempeño en cualquier trabajo de cierto nivel que implique adoptar decisiones de responsabilidad. Además, los sistemas sociales se caracterizan porque en ellos es recurrente el alejamiento parcial de las normas, los conflictos y las contradicciones, por lo que someter coercitivamente a la persona a lo que los demás esperan de él, supone una adaptación forzada que la deja en una posición vulnerable, subordinada y desventajosa. Desde este punto de vista, se plantea apoyar directamente a la persona, de manera no coercitiva, estimulando su iniciativa personal y con apoyo social de manera de lograr un grado más alto de realización personal directamente.

Revista de Ciencias Sociales - Número 69 (2016) - Universidad de Valparaíso - ISSN 0716-7725-Valparáís, Chile 
v. La discriminación a los que tienen otras opciones sexuales, a los que, entre otros muchos aspectos, se les niegan derechos a uniones civiles.

vi. La discriminación hacia personas con VIH SIDA.

vii. Etc., etc.

En la mayor parte de estos casos, las personas compiten en desventaja de condiciones por un trabajo y/o estudio de calidad. En el caso de las personas que se catalogan como "desviadas" se les aplican mecanismos de "control social" en que se intenta "adaptarlos" al sistema, aspecto que no da cuenta de la naturaleza dialéctica, con conflictos y oposiciones, de las relaciones sociales.

Las relaciones de discriminación y estigma, significan lo opuesto a empoderar a los individuos, significan dejarlos en posición subordinada en las relaciones microsociales de poder y dominación.

\section{Políticas de inclusión}

\section{a) El concepto de integración}

Según Rizo ${ }^{19}$ el concepto de ES tiene sus implicancias con conceptos acuñados desde la sociología clásica. Alienación y anomia, son conceptos que tienen un parentesco con el pasado analítico que tendría dicho término.

Si bien la ES es la condición no deseada, ubicada en el extremo negativo, su antípoda estaría situada en su versión deseada, que para el caso de Rizo (2006) es el concepto de integración.

La integración está referida a grupos sociales o colectivos amplios, y su origen está relacionado con la sociología norteamericana. La integración es definida con un indicador de medición social, el cual apunta a responder cuan está integrada a la sociedad determinados grupos. Es de esta manera que según Rizo ${ }^{20}$ encontraríamos 4 tipos de integración dentro de toda sociedad:

\footnotetext{
19. RIZO, ob. cit.

20. Íbid.
}

Facultad de Derecho y Ciencias Sociales - Universidad de Valparaíso - Chile 
A. Integración cultural: Concordancia entre las normas y la cultura.

B. Integración normativa: Conformidad de la conducta a las normas sociales.

C. Integración comunicativa: Intercambio de significados.

D. Integración funcional: Interdependencia debida al intercambio de servicios dentro de la división del trabajo.

El concepto de exclusión social implicaría una cierta imagen dual de la sociedad, en la que existe un sector integrado y otro excluido. Es este sector excluido el que queda al margen de una gama de derechos sociales, tales como laborales, educativos, culturales, entre otros ${ }^{21}$.

Como veíamos, en la tradición norteamericana frecuentemente se identifica la inclusión con el concepto de integración, haciendo la integración el opuesto a la exclusión. La integración se define en forma intersubjetiva, donde el concepto de institucionalización adquiere un papel central. Desde este punto de vista, respecto a los grupos:

i. Integración cultural: Se define a los grupos como integrados cuando las normas que guían la conducta de los miembros del grupo coinciden con las normas institucionalizadas de la sociedad.

ii. Integración normativa: Se define a las personas como integradas cuando el desempeño de los roles que ejecutan se ciñe a las normas institucionalizadas.

iii. Integración comunicativa: Se define al grupo como integrado cuando hay un buen proceso de comunicación o entendimiento, en el sentido que los significados que se transmiten son compartidos.

iv. Integración funcional: Se define a la sociedad como integrada cuando hay la suficiente reciprocidad en el intercambio de servicios por los lazos que crea la división del trabajo.

\section{JIMÉNEZ, ob. cit.}

Revista de Ciencias Sociales - Número 69 (2016) - Universidad de Valparáíso - ISSN 0716-7725-Valparáiso, Chile 
Si ello es así, tiende a identificarse el concepto de exclusión con el de desviación (respecto a las normas institucionalizadas), y hemos visto en la discusión de los roles que esta es una visión estrecha ya que hay amplios sectores de la conducta en todas las relaciones sociales que no están institucionalizados. Hay discordancias y conflictos, una dialéctica omnipresente entre las formas institucionalizadas y no institucionalizadas. Además, la comunicación nunca es perfecta, en todos los grupos hay niveles de discrepancias y conflictos y el intercambio, en sociedades "integradas" no siempre sigue patrones de reciprocidad. Las clases sociales tienen intereses parcialmente antagónicos que se expresan en la lucha política. Si la exclusión se identifica con desviación, los esfuerzos hacia la integración se identificarán con hacer más efectivo el control social. Las personas o grupos "desviados" aparecen como inferiores en la escala social y los esfuerzos por integrarlos a través del control social es lo opuesto a empoderarlos, más bien es des-empoderarlos, restarles iniciativa propia y "adaptarlos" al sistema. Ello deja a los grupos y personas "desviados" en posición de subordinación absoluta, hasta que dejen de ser desviados. Pero hemos visto que en sentido estricto todas las personas y grupos de la sociedad son "desviados", ya que las normas institucionalizadas sólo rigen parcialmente, siendo predominantes las discordancias, habiendo siempre oposiciones y conflictos. Visto así, la rotulación de "desviado" equivale simplemente a desempoderar o subordinar a la persona o grupo, para aplicarle un control social reforzado. Siendo asimétrica la distribución del poder en los grupos y la sociedad, reforzar los mecanismos de control social contribuirá a favorecer en mayor medida las posiciones sociales que gozan de mayor poder y/o privilegios.

Por ende este concepto contiene implícita una concepción que no compartimos, discrepando con $\operatorname{Rizo}^{22}$ respecto a que sea la situación contraria a la exclusión.

A diferencia de la teoría de la desviación, planteamos que lo que corresponde es empoderar a los individuos y grupos, lo que significa modificar las relaciones sociales que los ubican en la categoría de "desviados", modificando no sólo las características de las personas y

22. RIZO, ob. cit.

Facultad de Derecho y Ciencias Sociales - Universidad de Valparaíso - Chile 
grupos por los que los catalogan como "desviados", sino las relaciones por las que son excluidos, empoderándolos.

\section{b) El concepto de realización personal}

El plantear el concepto de exclusión social como una relación que dificulta e impide al sujeto ocupar una posición, superar una situación o ejercer un derecho, en el fondo es un juicio ético, en el sentido que quienes no ocupan la posición, no pueden superar una situación o no ejercen el derecho, deberían ocupar la posición, superar la situación o ejercer el derecho del que están excluidos.

Bajo este imperativo ético, consideramos que la concepción de la inclusión social debe considerar un concepto que reivindique el bienestar y capacidad de tener un rol activo y protagónico para ello de los individuos dentro de los sistemas sociales donde participan como sujetos y actores, por ello pensamos en su realización.

Desde este punto de vista exclusión o segregación significa que existen barreras para la realización de los involucrados como seres humanos, es decir de realizar sus intereses manifiestos. Pero como los seres humanos son, en cuanto a sus valores, aspiraciones e ideologías, muy distintos unos de otros, es impreciso hablar de realización humana en general y debemos introducir un adjetivo que dé cuenta de tales diferencias. El concepto de persona no considera a los individuos sólo como organismos biológicos, sino que supone que han sido socializados en una cultura en sentido antropológico, sin obviar, sino incorporando las diferencias individuales, y por tanto, pensamos que debe ser incorporado a la caracterización. Desde este punto de vista, y avanzando en la caracterización, podemos afirmar de que habrá exclusión o segregación cuando existan barreras que impidan la realización personal de los involucrados.

Pero esta caracterización no es suficiente. Lo que nos interesa y como se planteó más arriba no es la exclusión o segregación de uno u otro individuo aislado, sino la que afecta a un número definido de individuos en condiciones sociales similares, es decir, la exclusión y segregación social. Si, en el conjunto de individuos, por tratarse de situaciones, condiciones sociales o posiciones sociales similares se ven

Revista de Ciencias Sociales - Número 69 (2016) - Universidad de Valparáíso - ISSN 0716-7725-Valparaíso, Chile 
afectados por la exclusión y segregación social, esto significaría necesariamente que se trata de una segregación y exclusión social que si se mantiene en el tiempo tiene carácter estructural, ya que no depende de lo que sean los incumbentes individualmente sino que está asociada a su situación, condición social, o posición estructural, independientemente de quién ocupe esa posición o situación. Desde este punto de vista y parafraseando, podemos caracterizar la exclusión y segregación social como la situación social de un conjunto definido de individuos que ven notoriamente dificultada su realización personal por barreras sociales estructurales (precariedad de poder), que se manifiesta como una diferenciación física, material y social concreta así como un desvínculo social y mala calidad de relaciones sociales.

Creemos que casi todas las personas, a la hora de elegir, prefieren relaciones sociales de calidad, un trabajo digno, alcanzar una buena educación para ellos y sus hijos, vivienda de calidad en un sector urbano amigable, no ser discriminados por motivos sexuales, ideológicos, políticos, religiosos o por enfermedad mental o discapacidad.

¿Qué ocurre cuando las elecciones personales se basan en contravalores? Aquí hay que poner una restricción en la gama de valores elegibles. No cualquier valor social es aceptable, los valores elegibles no deben entrar en contradicción con tres valores básicos: el amor a la familia, el amor a la tarea u obligación social (trabajo, estudio o roles de dueña de casa cuando corresponda), y un mínimo de vocación hacia la sociedad o solidaridad social, lo que no excluye posibles conflictos o contradicciones entre estos tres tipos de valores.

¿Por qué decimos que estos tres tipos de valores son un mínimo imprescindible? Toda sociedad actual y futura, capitalista, socialista, postmoderna o la que fuera: (1) no eliminará la familia, lo que lleva la contrapartida a nivel personal de una motivación basada en valores que robustezcan o mejoren, eliminado los obstáculos negativos, el grupo familiar (amor a la familia) ... el amor a la familia no significa aceptar las relaciones familiares tal como se dan, puede significar oponerse a ellas cuando son injustas o incluso buscar una nueva familia con relaciones que permitan la realización personal de sus miembros; (2) no eliminará el trabajo o la tarea u obligación social, que para que la sociedad se desarrolle debe ser desempeñado eficientemente, lo que

Facultad de Derecho y Ciencias Sociales - Universidad de Valparaíso - Chile 
pone en primer plano el amor a la tarea para (i) que existan motivaciones individuales que la refuercen y (ii) que los individuos se sientan satisfechos o realizados desempeñándola; (3) sin un mínimo de solidaridad, respeto al prójimo o como se llame, ninguna sociedad puede funcionar adecuadamente sin caer en la guerra de todos contra todos.

Con esto no estamos defendiendo esta sociedad en particular, aún más, debemos preguntarnos si la sociedad actual, con las oportunidades que ofrece, promueve estos valores necesarios. La misma segregación y exclusión de grandes grupos sociales estimula el surgimiento de contravalores, como en el caso de la delincuencia, que se ve notablemente estimulada por las condiciones de exclusión y falta de oportunidades educacionales y de trabajo accesible hacia el cual se pueda sentir "amor", pero eso no significa de ninguna manera que los contravalores delictivos sean aceptables ni tampoco que dejen de hacerse los máximos esfuerzos por remover las barreras que generan dichos contravalores. La promoción del amor a la familia, el amor a la tarea y la solidaridad social, pasan necesariamente por un enfoque crítico y transformador de la sociedad actual, pero al mismo tiempo, debe considerárselos fundamentales.

Si examinamos el problema empleando los conceptos introducidos más atrás, ¿qué significa estar impedido de lograr la realización personal?

La realización personal es sinónimo de lograr los intereses manifiestos, y la capacidad de lograr los intereses es sinónimo de tener poder, desde este punto de vista, como hemos definido, el concepto de exclusión es sinónimo de ausencia o carencia de poder, y por tanto depende de las relaciones de poder que se den dentro de la sociedad y dentro de los sistemas de interacción en que participan las personas. Como el poder se relaciona, aunque es distinto a las relaciones de dominación, pero puede ejercerse en algunos casos a través de relaciones de dominación, la exclusión se relaciona también de alguna manera a las relaciones de dominación, sobre todo cuando la carencia de poder depende de relaciones de dominación simbólicas como ocurre en los casos de subordinación debidas a la estigmatización social.

Revista de Ciencias Sociales - Número 69 (2016) - Universidad de Valparaíso - ISSN 0716-7725-Valparáís, Chile 


\section{c) Políticas legítimas de inclusión}

Las políticas de inclusión deben contar con la participación organizada, informada y en igualdad de condiciones respecto a la participación en las decisiones, de los sectores, grupos o personas involucrados. En este sentido significa transformar las relaciones para darle más poder real a los sectores, grupos o personas involucrados.

En el plano individual, deben basarse en la realización personal, como criterio ético-social, antes que en la adaptación social.

El concepto que debe guiar los esfuerzos por reintegrar a la persona logrando una inclusión social que respete la diversidad, como se ha fundamentado es el de realización personal. Hemos desarrollado el concepto que tiene su base, aparte de su fundamento ético en conceptos teóricos. Un componente necesario para que nos realicemos es que a través de nuestra conducta tengamos un reconocimiento social (como afirma el sociólogo George Mead) ${ }^{23}$, nuestra satisfacción interior depende de los demás. Además, como lo plantea Max Weber ${ }^{24}$, las grandes metas que se plantean los hombres no surgen de la nada, son metas elaboradas socialmente.

¿Esto significa que el concepto de realización personal coincide con el de adaptación social? No es así porque:

1. El reconocimiento puede ser en algunos aspectos y no en otros.

2. El reconocimiento puede ser no de los más próximos a la persona, pero deben ser metas en lo general (no en lo específico) consideradas valiosas por un sector apreciable de la sociedad (por ejemplo la profesión de profesor de la enseñanza básica es valorada socialmente, puede que la familia la considere poco remunerativa desde el punto económico, y en lo específico la persona puede innovar en las materias que dicta).

23. MEAD, George: Espíritu, Persona y Sociedad. Bs. Aires, Paidós. 1968.

24. WEBER, Max: Economía y sociedad. México, Fondo de Cultura Económica. 1997.

Facultad de Derecho y Ciencias Sociales - Universidad de Valparaíso - Chile 
3. A esas metas, se les da un contenido personal que puede no ser compartido con otros, debiéndose dejar las decisiones específicas a la persona que está inmersa en la situación y que muchas veces no pueden establecerse desde fuera

Pero esto no significa que la persona sea apoyada en metas absolutamente irrealizables en un plazo mediano. Se lo puede ayudar a tener una estrategia, impulsarlo a alcanzar metas más pequeñas que vayan conduciendo a las metas mayores, de acuerdo a sus valores y concepción de la vida. No basta con que la persona se plantee una meta valorada socialmente; para realizarse personalmente debe tener logros, sin que ello signifique que estos logros sean completos y los más altos.

El concepto de realización personal no sólo da una perspectiva ética a la inclusión, sino que es un corolario de todos los derechos. Para realizarse personalmente el individuo debe tener la posibilidad real de trabajar remuneradamente según su vocación y con una remuneración digna que le permita formar la familia que escoja, lo que implica educación, una vivienda o habitación digna y acogedora y la concreción, que está lejos de alcanzarse, de todos los derechos humanos fundamentales y todo esto debe lograrse, lo que es muy importante y queremos destacar, según sus valores, los que le dan sentido a nuestra vida, como seres únicos e irrepetibles.

Las políticas de inclusión, para que tengan un sentido ético y ser conceptualmente correctas, deben tener algunas características mínimas:

i. Que no vayan contra, y mejor aún, que contribuyan a realizar las aspiraciones más sentidas por las personas, y no ser impuestas desde fuera, siempre que esas aspiraciones se enmarquen en valores sociales de un sector apreciable de la sociedad, aunque no sean los valores de quien dirige el proceso de inclusión o los que tienen posiciones de poder o autoridad en ese proceso, y

ii. Cuando se trata de sectores amplios de la sociedad, que se les dé una participación real en las decisiones a las organizaciones derivadas de base que los representan, organizaciones derivadas ya definidas en la introducción

Revista de Ciencias Sociales - Número 69 (2016) - Universidad de Valparáíso - ISSN 0716-7725-Valparáiso, Chile 
conceptual, debidamente informadas y asesoradas por expertos que interpreten realmente sus anhelos y aspiraciones más profundas, sin imposiciones arbitrarias.

iii. En los casos i e ii, el que se otorgue poder real a los individuos, conjuntos de individuos y organizaciones que representan a las categorías sociales que carecen de dicho poder. Desde este punto de vista, eliminar o reducir la exclusión es sinónimo de empoderar a los individuos afectados y a las organizaciones que los representan.

Debemos referirnos de manera un poco más extensa a los puntos ii e iii. Una de las soluciones al problema ético de la exclusión de amplios sectores sociales se plantea a través de la participación a través de consultas ciudadanas o en organismos estatales o municipales como consejos de desarrollo local, pero esto es insuficiente por sí solo. Una participación real involucra que existan organizaciones derivadas de base fuertes y empoderadas que los representan independientes del Estado y que cuenten con asesores profesionales, cuando se requiera, que sean sólo fieles a ellas. Si no existen este tipo de organizaciones estos sectores no tendrán capacidad real de oponerse si no son escuchados o en otros casos serán simplemente correas de trasmisión de políticas desde arriba en relaciones de poder de las que siguen excluidos, siendo la única manera de evitarlo que ellas tengan la fuerza para ejercer su poder y que estas sean reconocidas como interlocutores válido por las organizaciones estatales y privadas. Para ilustrar el problema podemos referirnos a las políticas de salud en Brasil, en que se garantiza la participación de la población en la discusión de las políticas de salud en consejos locales estatales. ¿Pero qué ocurre en realidad? Las políticas de salud son formuladas a nivel central por profesionales de la salud que son expertos en el tema y se ha constatado que por esa razón la participación en la discusión de dichas políticas por la población lega es mínima, prácticamente inexistente, por lo que esos consejos locales son meramente correas de transmisión de las políticas oficiales. Distinto sería el caso si hubiera organizaciones derivadas de bases fuertes, independientes y reconocidas por el Estado y que contaran con profesionales expertos fieles sólo a ellas que las asesoraran, explicaran educativamente

Facultad de Derecho y Ciencias Sociales - Universidad de Valparaíso - Chile 
las diversas consecuencias no previstas, recogieran y ayudaran a una formulación más fundamentada de sus inquietudes que la población lega no sabe expresar formalmente, estando las decisiones finales de los planteamientos en el conjunto de las organizaciones de base y no sólo en los expertos.

\section{Conclusiones}

Hemos analizado diversos enfoques del concepto de exclusión e inclusión social, considerando que respecto a dicho concepto existen ambigüedades. Basados en un enfoque teórico de nuestra autoría ${ }^{25}$ intentamos una definición más precisa y general, tanto del concepto como de criterios válidos ética y socialmente de inclusión, que evita confusiones teóricas y formas cuestionables de políticas afines como las de "integración social”. Esperamos haber contribuido con un aporte en que partiendo de un concepto de moda este pueda ser precisado para usarlo en políticas sociales con justicia social.

25. CHUAQUI, Jorge: Microsociología y estructura social global. Lom, 2012.

Revista de Ciencias Sociales - Número 69 (2016) - Universidad de Valparáíso - ISSN 0716-7725-Valparáiso, Chile 
Jorge Chuaqui, David Mally y Ruby Parraguez

\section{BIBLIOGRAFÍA}

BARROS, P., Ríos, D., Torche, F. : Lecturas sobre la Exclusión Social. Organización Internacional del Trabajo (OIT). Santiago de Chile. 1996.

BECK, Ulrich: La sociedad del riesgo. Paidós, 1998.

BERGER, Peter y Luckmann, Thomas: La construcción social de la realidad, Editorial Akal. 2001.

BOURDIEU, Pierre : Los intelectuales, política y poder, Buenos Aires: Editorial Eudeba. 2003.

CHUAQUI, Jorge: Microsociología y estructura social global. Lom, 2012.

FABRE, M.: Consideraciones en torno al concepto de exclusión social. Acciones e investigaciones sociales. Universidad de Zaragoza. 2002.

JIMÉNEZ, M.: "Aproximación teórica de la exclusión social: Complejidad e imprecisión del término. Consecuencias para el ámbito educativo". En: Revista Estudios Pedagógicos. No 1. Pp. 173-186. 2008.

LAPARRA, M., Obradors, A., Pérez, B., Péres Yruela, M., Renes, V., Sarasa, S. Subirats, J., Trujillo, M. (s/a). Una propuesta de Consenso sobre el concepto de exclusión. Implicancias metodológicas. Trabajo Preliminar del VI informe FOESSA.

MEAD, George: Espíritu, Persona y Sociedad. Paidós, 1968.

RIZO, A.: “¿A qué llamamos exclusión social?” Polis, En: Revista de la Universidad Bolivariana. No 015. Pp. 1-14. 2006.

SARMIENTOS, J.: "Exclusión social y ciudadanía política. Perspectivas de las nuevas democracias latinoamericanas". En: Revista Última

Década. No 8, pp. 53-69. 1998.

WEBER, M.: Economía y sociedad. (2a ed.) México: Fondo de Cultura Económica. 1997.

Facultad de Derecho y Ciencias Sociales - Universidad de Valparaíso - Chile 